Röhrchen aus schwer schmelzbarem Glase verbunden*) welches, um eine Condensation der Ameisensäure zu verhindern, vor und während des Durchstreichens der Dämpfe auf etwa $100^{\circ}$ erhitzt wird.

Wenn die Reduction beendet ist, leitet man etwa 20 Minuten lang einen starken Strom trockner Kohlensäure über das nun stärker erhitzte Kupfer und bewahrt es dann in derselben gut zu verschliessenden Röhre zum Gebrauch auf. Wenn es nicht lange nach der Darstellung verwandt wird, so ist ein nochmaliges Erhitzen vor dem Einfüllen in das Verbrennungsrohr nicht nöthig.

Eine auf ähnlichem Princip beruhende Methode zur Reduction von Kupferdrahtnetzspiralen, die sich durch ihre ausserordentliche Einfachleit auszeichnet, ist, wie mir von verschiedenen Seiten mitgetheilt wurde, in den Universitäts-Laboratorien zu München und zu Genf in Gebrauch. Man glüht die Spirale über dem Gebläse und lässt sie noch glïhend in ein Reagensglas. fallen, das $2-3$ Tropfen Methylalkohol enthält. Dieser wird in Dampf verwandelt und bewirkt vollständige Reduction. Nach dem Erkalten trocknet man die Spirale bei $140^{\circ}$. Statt des Methylalkohols lässt sich wohl auch Aethylalkohol verwenden, dagegen soll z. B. Aether oder Essigsäure zur Reduction nicht geeignet sein.

II. Chemische Analyse anorganischer Körper. Von

\title{
E. Hintz.
}

Ueber das Spectrum des Magnesiums haben G. D. Liveing und J. Dewar**) eingehende Untersuchungen ausgeführt, bezüglich deren ich mich mit dem Hinweis auf die Originalabhandlung begnügen muss.

Ein empfindliches Reagenspapier auf gasförmiges Ammoniak hat Gustav Kroupa ***) angegeben.

Löst man Fuchsin in Wasser und setzt verdünnte Schwefelsänre $z a$, so geht die rothe Farbe der Lösung in gelbbraun uber. Mit einer

*) Der Kolben und die Verbrennungsröhre dürfen nicht mit Kautschukstopfen, sondern nur mit Korkstopfen verschlossen sein.

**) Proc. Roy. Soc. 32, 189. - Beibl. z. d. Ann. d. Phys. u. Chem. 6, 96.

***) Chemikerzeitung 5, 952 . 